\title{
GEODIVERSIDADE E GEOTURISMO NO ESTADO DE RORAIMA
}

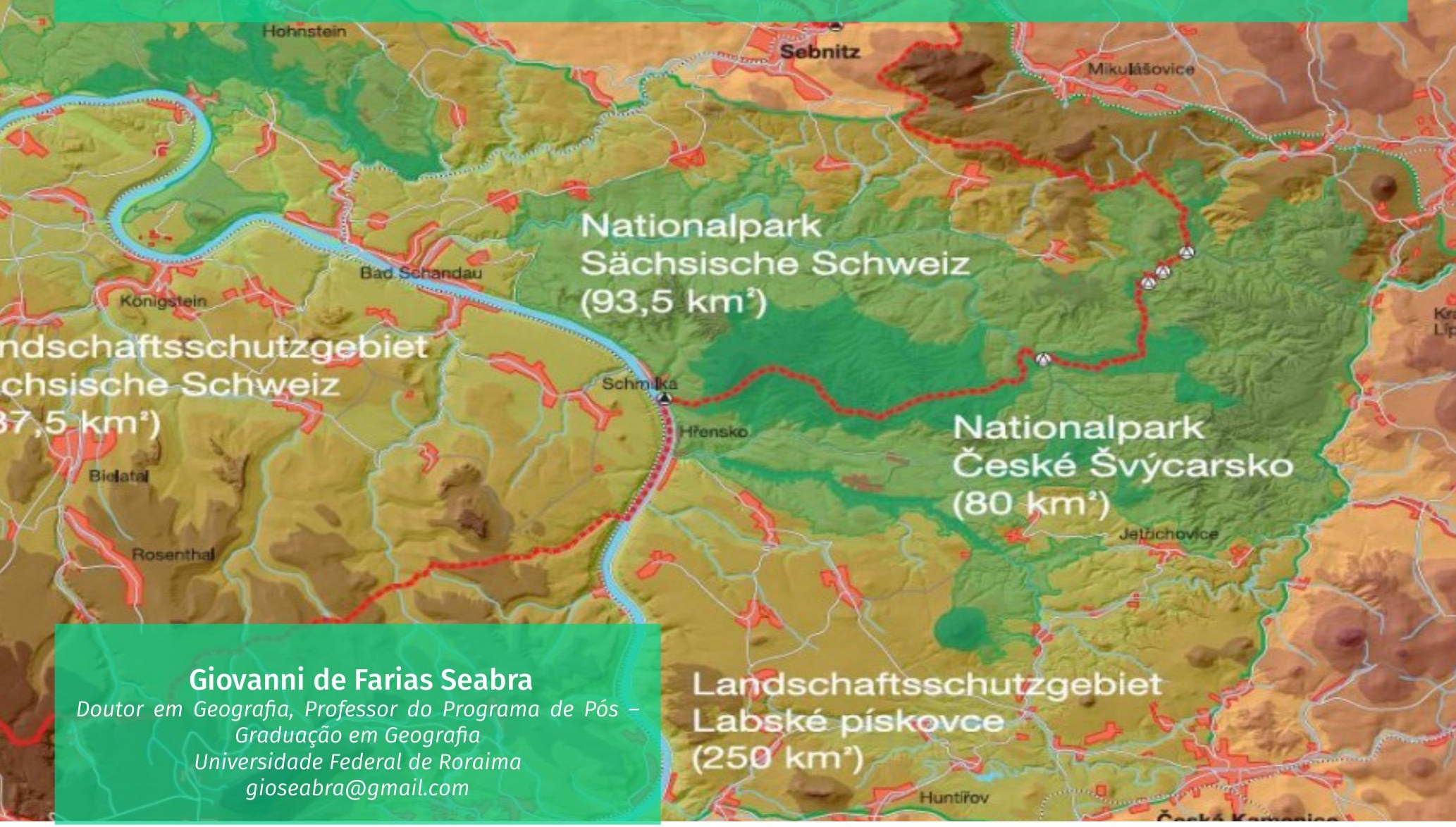

\section{RESUMO}

O presente trabalho é produto de uma pesquisa, ainda insipiente, sobre o potencial geoturístico do estado de Roraima. Ao contrário do que se propaga no meio acadêmico brasileiro, que apresenta o geoturísmo como temas recentes, o turismo ecológico de base geológica remonta ao século $\mathrm{XX}$, pelo menos, conforme registros no National Park SächsischeSchweiz, localizado na região da Bohêmia, ocupando os territórios alemães e tchecos situados às margens do rio Elba. No estado de Roraima, os atrativos geoturísticos estão dispersos e integram, principalmente, terras indígenas, unidades de conservação e propriedades privadas, sendo necessários estudos mais aprofundados para identificação e delimitação dos geossítios, bem como o uso turístico das morfoesculturas e dos acervos paleontológicos e arqueológicos.

Palavras - chave: Geodiversidade, Geoturismo, Morfoesculturas, Termiteiros.

\section{RESUMEN}

El presente trabajo es producto de una investigación, aún insipiente, sobre el potencial geoturístico del estado de Roraima. Contrariamente a lo que se propaga en el medio académico brasileño, que presenta el geoturismo como tema reciente, el turismo ecológico de base geológica se remonta al siglo XX, al menos, según registros en el National Park Sächsische Schweiz, ubicado en la región de Bohemia, ocupando los territorios alemanes y checos situados a orillas del río Elba. En el estado de Roraima, los atractivos geoturísticos están dispersos e integran, principalmente, tierras indígenas, unidades de conservación y propiedades privadas, siendo necesario estudios más profundizados para la identificación y delimitación de los geosítios, así como el uso turístico de las morfoesculturas y de los acervos paleontológicos y arqueológicos.

Palabras clave: Geodiversidad, Geoturismo, Morfoesculturas, Termiteiros. 


\section{INTRODUÇÃO}

A paisagem é um conjunto de elementos físicos, biológicos e socioeconômicos inter-relacionados, visiveis aos olhos, que caracterizam uma determinada porção do espaço geográfico. Paisagem é tudo que a vista alcança, ou seja, numa abordagem conceitual, é "uma determinada porção do espaço, resultado da combinação dinâmica e instável, de elementos físicos, biológicos e antrópicos que fazem dela, a paisagem, um conjunto único e indissociável, em perpétua evolução" (BERTRAND, 1971).

São componentes da paisagem as formas de relevo, os tipos climáticos, a cobertura vegetal, a biodiversidade, os solos desprovidos de vegetação, os campos povoados de animais ou cultivares, os rios e córregos, vilas e cidades, e as diversas formas de ocupação humana, quando houver.

Ao abordar a paisagem neste trabalho, priorizamos as estruturas geológicas e as morfoesculturas do relevo, denominadas "relevos estruturais" e "relevos esculturais" (ROSSI, 1996) ou, simplesmente, "geodiversidade" (BRILHA, 2005), ou seja:

[...] a variedade de ambientes geológicos, fenômenos e processos ativos que dão origem à paisagens, rochas, minerais, fósseis, solos e outros depósitos superficiais que são o suporte para a vida na Terra (BRILHA, op. Cit., pág, 17).

Os relevos estruturais são macrounidades da paisagem com extensão de algumas centenas de quilômetros, permitindo a eles, em nível metodológico para ordenamento territorial, tratamento geossistêmico, ou geoecológico, aplicados ao planejamento ambiental e turístico. Assim, apresentamos oscompartimentos geomorfológicos de Roraima, estado federativo localizado no extremo norte amazônico do território brasileiro, assim como as estruturas geológicas, a geodiversidade e as geoformas, como principais atrativos para o desenvolvimento do geoturismo, o qual, para ser viabilizado como atividade produtiva, urge ações para a geoconservação.

Geodiversidade,

geoconservação

e geoturismo são conceitos recentes no mundo acadêmico, especialmente a partir dos anos 1990, cuja essência, tanto de um como de outro, todavia pertence ao lazer e imaginário de antigas civilizações européias e asiáticas. Já no século XVIII monumentos geológicos entremeados de vales labirínticos eram visitados turisticamente nas margens esquerda e direita do rio Elba, nos territórios da Alemanha e da República Tcheca, compreendendo a Região da Bohêmia, com destaque para as morfoesculturas em arenito e as pontes de pedra, atualmente onde está instalado o Nationalpark Sächsische Schweiz (Figura 1).

$\mathrm{Na}$ segunda metade do século XIX a Região da Bohêmia instalou equipamentos exclusivamente para 0 atendimento aos turistas, como abertura e construção de escadarias nas trilhas e caminhos de acesso aos monumentos geológicos, sinalização, e abertura de pousadas, restaurantes e cafés. Posteriormente, no início do século $X X$ foi construído um elevador para atender ao fluxo de visitantes (Figuras 2 e 3 ).

A nosso ver, geoturismo é uma derivação do ecoturismo com ênfase nas morfoesculturas do relevo, incluindo informações sobre a gênese, estrutura e morfodinâmica da rocha. Na observância dos conceitos e definições de um e de outro, as semelhanças são evidentes, senão vejamos:

O ecoturismo é definido como a prática de turismo de lazer, esportivo ou educacional, em áreas naturais, que se utiliza de forma sustentável dos patrimônios natural e cultural, incentiva a sua conservação, promove a formação da consciência ambientalista e garante o bem estar das populações envolvidas (MIC / Embratur, 1994). 


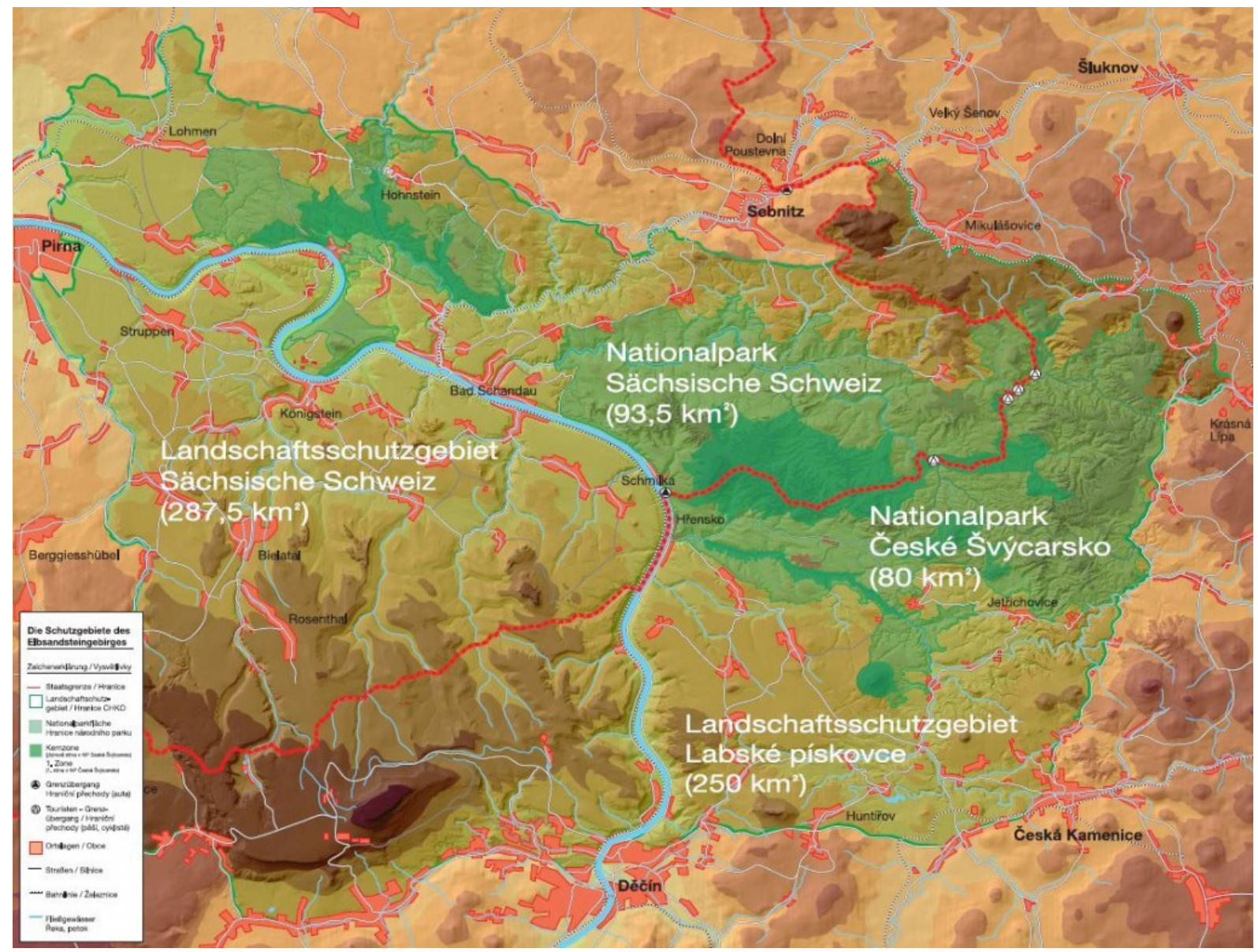

Figura 01: Bohemian National Park Region

Fonte: Nationalpark-Saechsische-Schweiz, 2019.
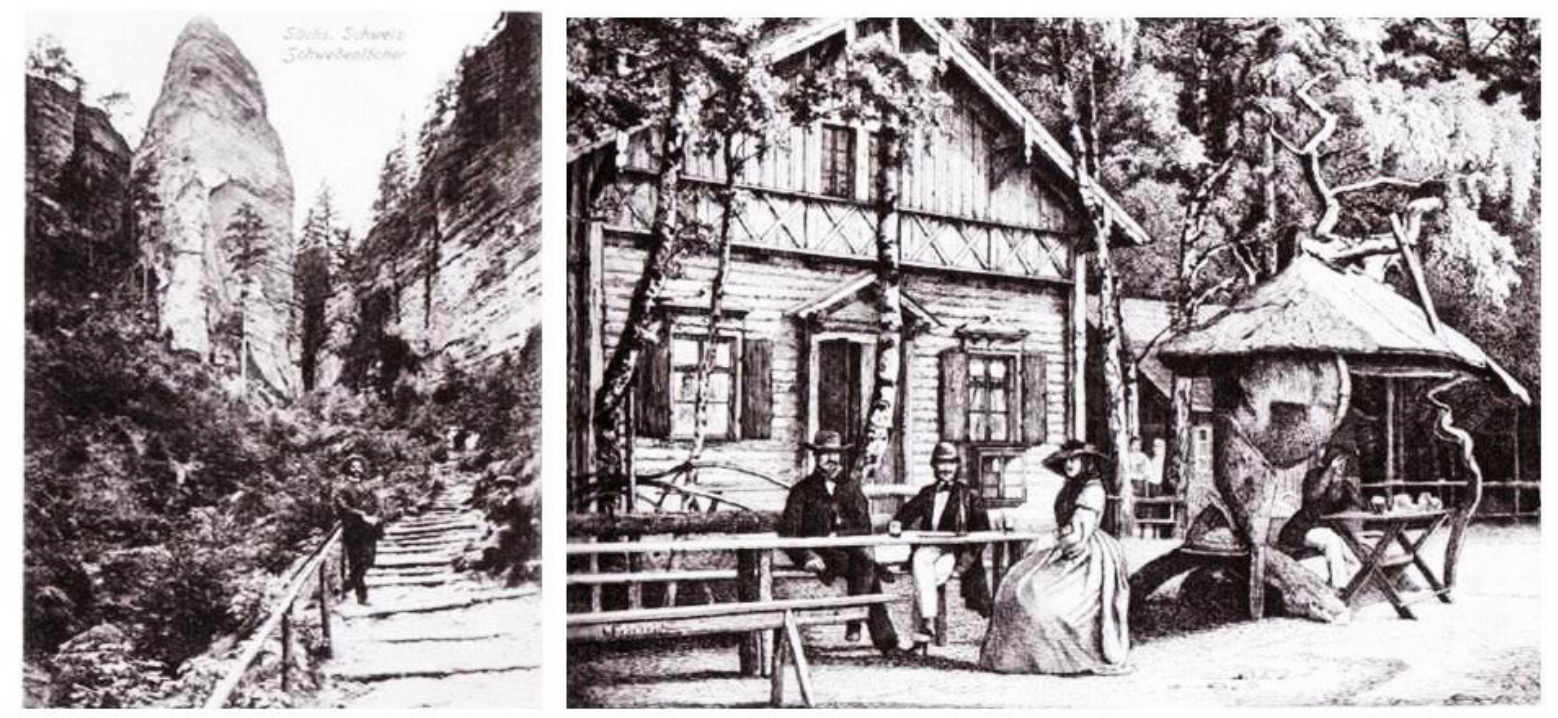

Figuras 2 e 3. As imagens revelam estruturas de acesso aos geomonumentos e os equipamentos turísticos (hospedagem e restaurante) para acolhimento dos ecoturistas, em 1886

Fonte: Rölke, 2006b.

Sem embargo, o ecoturismo seguiria consciência ambiental e sustentabilidade uma rota diferenciada dos padrões ecológica, social, econômica e cultural. Por usuais do turismo, uma vez que envolve a definição, o diferencial deste segmento 
turístico compõe um leque de fatores, principalmente as componentes ecológica e social, portanto em franco desacordo com as estratégias governamentais de valoração e comercialização do espaço natural através da promoção do dito ecoturismo massificado em áreas protegidas da natureza. Os oportunismos políticos para captação de recursos, com o uso dos conceitos de ecoturismo, são visivelmente identificados nos textos dos projetos oficiais enviados aos bancos e órgãos de fomento ao turismo.

Por ser uma atividade de lazer socialmente diferenciada, o ecoturismo não obedece simplesmente à lógica de mercado. É uma viagem solidária e responsável, dirigida às áreas naturais e comunidades tradicionais, com o fim de conservar o meio ambiente e promover o bem estar dos povos locais, especialmente os mais humildes e excluídos do eixo econômico. Portanto, abrange o meio ambiente em todos os seus aspectos, como a paisagem natural, a componente social e o patrimônio cultural. No Brasil, o ecoturismo é evidenciado desde 1985, atendendo à forte demanda oriunda da multiplicação dos parques nacionais, priorizando-se 0 uso turístico em detrimento da conservação ambiental.

O geoturismo, por sua vez, é uma atividade de lazer e entretenimento, baseada na geodiversidade, que utiliza as feições geomorfológicas como o principal atrativo turístico. Todavia, na maioria das vezes, o geoturismo está associado a outros aspectos da paisagem como rios, lagos, cachoeiras, vegetação, bem como instalações, equipamentos e serviços turísticos. Na prática, trata-se de um conceito difuso, superposto ao ecoturismo, com ênfase na paisagem, envolvendo os aspectos tanto naturais cavernas, vulcões, mirantes, esculturas rochosas, dunas; como culturais - monumentos líticos, calçamentos, alicerces e paredes das edificações, lápides de cemitérios, etc. Porém, nem todas as definições de geoturismo se relacionam, de modo inequívoco, com a geodiversidade (BRILHA, 2005).

Segundo a Travel Industry Association of America (TIA), o geoturismo é definido como o turismo que apoia ou valoriza as características geográficas do lugar em foco, incluindo-se o meio ambiente, cultura, a herança estética e o bem estar da população local (ALFAMA, 2007). De acordo com a National Geographic Society (NGS) apud Brilha (2005), o geoturismo procura minimizar o impacto cultural e ambiental sobre as comunidades que recebem fluxos turísticos, inserindose no conceito mais abrangente de turismo sustentável.

No presente trabalho apresentamos alguns aspectos da geodiversidade, geoconservação e geoturismo no Estado de Roraima. Em nível local, enfatizamos os geossítios, onde se destacam as inscrições rupestres e as ocorrências dos termiteiros "pagodes", onde são evidenciados os edificios dos cupins cuja bioarquitetura se destaca na paisagem do lavrado.

Vale salientar que o patrimônio natural do estado de Roraima, notadamente a geodiversidade e a biodiversidade, está sendo dizimado, seguindo o triste exemplo da Mata Atlântica brasileira, a passos acelerados, pelo ferro e pelo fogo (Figura 4) (WARREN, 2013).

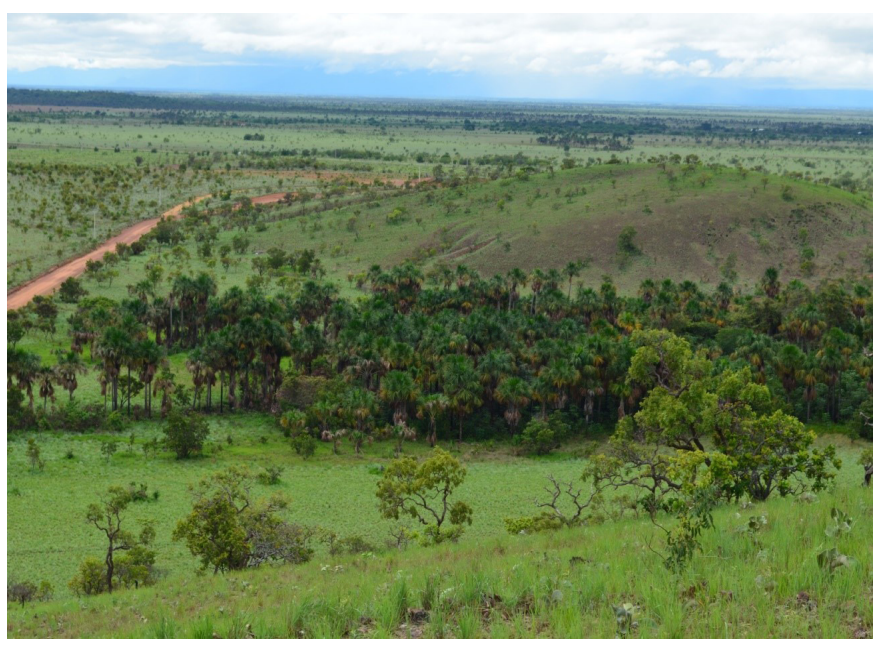

Figura 04: Paisagem típica do lavrado, estado de Roraima, municipio de Bonfim-RR Fonte: Giovanni Seabra, 2019. 


\section{METODOLOGIA}

De acordo com Bertrand (1971), geossistema é uma determinada porção do espaço, sendo resultado da combinação dinâmica e instável dos elementos físicos, biológicos e antrópicos, que fazem da paisagem um conjunto único e indissociável em perpétua evolução. O autor destaca que o estudo da paisagem só pode ser realizado no quadro da Geografia Física Global, estabelecendose critérios taxonômicos, ou seja, quando a paisagem é subdividida hierarquicamente, segundo a homogeneidade, comportamento e funcionalidade de seus componentes.

O lugar, por sua vez, é um espaço afetivo com limites geoecológicos, resultado da combinação dos componentes naturais e culturais num determinado território evidenciado na paisagem. No ordenamento territorial, as diferenciações existentes na paisagem, em nivel regional e local, que caracterizam o lugar, são espacialmente individualizadas em unidades geoecológicas para fins de planejamento ambiental e turístico. O planejamento territorial, numa abordagem sistêmica e descentralizada propicia a inclusão social, o desenvolvimento local e a integração regional.

Ao introduzir o termo geossistema na literatura soviética, SOTCHAVA (1972) concebeu a conexão da natureza com a sociedade e seus aspectos dinâmicos num determinado espaço, levando-se em consideração todos os fatores econômicos e sociais influenciando sua estrutura e particularidades espaciais. Através dessa metodologia, são estabelecidos critérios dimensionais e hierárquicos de unidades espaciais homogêneas denominadas geossistemas e suas subdivisões. A integração dos componentes geossistêmicos naturais, econômicos e culturais incentiva a inserção de novos serviços e produtos na economia local, impulsiona a cadeia produtiva e promove a elevação do padrão de vida da comunidade residente.

Para o presente trabalho de pesquisa adotamos a metodologia geossístêmica, destacando as subunidades em nivel de geótopos, correspondendo aos geossítios, abrangendo alguns hectares, onde identificamos ocorrências de geomonumentos, como os sítios rupestres e os termiteiros "pagodes" com elevada densidade espacial. Essas estruturas, de natureza cultural e biológica, de inestimável valor paleozoico, faunístico, ecológico, arqueológico e cultural, estão severamente ameaçadas pelos impactos causados pelo vandalismo contumaz, o modelo de exploração rural que "tratoriza" tudo o que encontra pelafrente, impondo mudanças ambientais irreversiveis na paisagem do lavrado, tornando-o biologicamente estéril e monótono.

\section{RESULTADOS E DISCUSSÕES}

No interior do Brasil, o relevo é originário de intensa atividade tectônica que reativou os dobramentos e abriu centenas de falhas e fraturas. Em seguida houve rebaixamento do relevo, ocasionado por sucessivos processos erosivos formando extensas áreas aplanadas denominadas pediplanos e peneplanos, respectivamente em climas semiáridos e semiúmidos. Movimentos tectônicos, variações climáticas, litologias variadas e erosão diferencial esculpiram morfologias residuais testemunhando a ocorrência de superficies outrora mais elevadas. Tais elevações superiores ao piso circundante são apelidadas serras, morros testemunhos e inselbergues, que surgem quebrando a monotonia dos pediplanos roraimenses. São exemplos clássicos de testemunhos no estado o morro Redondo e o morro da Antena, ambos no município de Bonfim. Os aspectos geológicos geomorfológicos da paisagem configuram-se comi importantes destinos geoturístcos no Brasil e no mundo.

Existem roteiros geoturísticos 
consagrados há décadas no Brasil, implantados com objetivos geológicos, geomorfológicos, ecológicos, pedagógicos e científicos. É destaque no geoturismo asvárias geoformas de superficie, como as montanhas, chapadas, serras, inselbergues, cânions, lajedos, matacões, boqueirões, furnas, pedras furadas e cavernas, somente para citar alguns. Há décadas, tais atrativos são objetos de contemplação, lazer e recreação dos ecoturistas sendo, portanto, regiões geoturísticas consolidadas a Chapada do Araripe (CE, PI, PE), a Gruta de Ubajara, os Monólitos de Quixadá e o Geoparque de Santana do Cariri (CE), o Cânion do São Francisco (BA, SE), a Chapada Diamantina (BA), o Parque Estadual de Vila Velha (PR), o Parque Nacional Serra da Capivara e o Parque Nacional de Sete Cidades (PI), somente para citar alguns (SEABRA, 2007b). Os locais apontados constam dos roteiros turísticos em função da exuberância paisagística e diversidade cultural, atraindo fluxos permanentes de visitantes.

Os espaços geográficos do estado de Roraima irradiam belezas cênicas extraordinárias, evidenciadas nas formações estruturais e formas esculturais do relevo. Esses lugares são habitados por grupos populacionais especiais, como os povos originários nos territórios indígenas, as comunidades ribeirinhas e os produtores rurais tradicionais, cuja lide campesina é baseada na pequena produção familiar diversificada nos criatórios de animais, peixes, extrativismo e policultura.

Tomamos caracterização como da geodiversidade a Roraima a zona climática equatorial, onde estão inseridos os dois grandes domínios morfoclimáticos correspondentes às duas unidades morfoestruturais, representadas pelos Terrenos Proterozóicos do Escudo das Guianas e as Coberturas Sedimentares Fanerozóicas. Esses compartimentos geológicos são subdivididos em unidades morfoesculturais menores (LADEIRA e DANTAS, 2014), aqui considerados unidades geoecológicas ou geossistemas (SEABRA, 2014):

Terrenos Proterozóicos do Escudo das Guianas: Planalto do Interflúvio Amazonas - Orenoco; Planalto Sedimentar de Roraima; Planalto Dissecado Norte da Amazônia; Planaltos Residuais de Roraima; Depressão Marginal Norte do Amazonas;

Coberturas Sedimentares Fanerozóicas: Depressão de Boa Vista; Pantanal Setentrional.

O Planalto do Interflúvio Amazonas Orenoco é uma área montanhosa moldada em rochasígneas e metamórficas, onde despontam as maiores altitudes do estado. Do ponto de vista da geodiversidade são evidenciadas as superficies de cimeira com topos aplanados, com cotas superiores a $1.500 \mathrm{~m}$. Tais morfoesculturas são denominadas "tepuys", a exemplo do monte Caburaí, onde está situado o ponto extremo norte do território nacional. Outros atrativos turísticos são oriundos dos morros escalonados, dissecados e cortados em vales profundos que servem de suporte a um grande número de rios, corredeiras e cachoeiras. Culturalmente, esse geossistema pertence aos territórios indígenas das etnias Yanomami e Macuxi, motivo pelo o qual o ingresso de visitantes é restrito. Exceção é a cidade de Uiramutã, um enclave não índio no interior da terra indígena Raposa - Serra do Sol.

O Planalto Sedimentar de Roraima é modelado em chapadas, cuestas, hogbacks e platôs com degraus estruturais e rebordos erosivos, com instalação de voçorocas bem desenvolvidas e grande movimentação de terras nos solos desprovidos de vegetação causados pela mineração. Em terras da União, fronteiriça com a Venezuela está instalada a vila de Tepequém, no município de Amajari, um dos principais pontos turísticos do estado. A unidade estrutural abrange o monte Roraima, com $2.734 m$ de altitude, área protegida, onde 
está instalado o Parque Nacional de Monte Roraima.

O Planalto Dissecado Norte da Amazônia é emoldurado ao norte e a oeste pelo Planalto do Interflúvio Amazonas-Orenoco; ao sul limita-se com os Planaltos Residuais de Roraima e a leste com a Depressão Marginal Norte da Amazônia. A área é caracterizada pela presença de superficies aplainadas degradadas ou retocadas em colinas suaves e morros residuais baixos. Aqui e acolá surgem esparsamente mesetas, cristas e pontões. Os dois principais rios, Mucajaí e Urariquera, formadores do rio Branco, correm em vales encaixados tropeçando nas corredeiras e cachoeiras.

Os Planaltos Residuais de Roraima correspondem aos fragmentos das superficies mais elevadas dispersos no Planalto Dissecado Norte da Amazônia e na Depressão Marginal Norte do Amazonas. O relevo é esculpido em rochas ígneas e metamórficas, intensamente fraturadas e falhadas, atingindo altitudes entre 400 e 1500 metros, destacando-se as serras Acaraí, Grande,Balata, Prata,Apiaú, Caracaraí, Mocidade, Anauá e Gurupira. As serras do Mucajaí, Ipiranga e Serrinha formam cristas montanhosas e pontões, com vertentes ingremes e ravinadas. Na região minam as nascentes do rio Mucajaí, cuja margem direita emerge a serra do Apiaú, compondo um conjunto de cristas e pontões com altitudes até 1500 metros.

A serra da Mocidade é um maciço residual situado no interior do Parque Nacional Serra da Mocidade. Consiste num conjunto de cristas com altitude média de 800 metros, onde nascem os rios Catrimâni, Água Boa do Univini e Ajarani, tributários da margem direita do baixo Rio Branco. O Parque Nacional Serra da Mocidade é limítrofe à Terra Indígena Yanomami e ambos requerem esforços governamentais para a preservação da malha hídrica, geodiversidade, biodiversidade e o patrimônio cultural.

A Depressão Marginal Norte do
Amazonas é a maior unidade morfoescultural de Roraima, consistindo num vasto pediplano, com altitudes entre 80 e 160 metros, declinando suavemente na direção sulsudoeste. Ocupa $31 \%$ do território estadual, sendolimitada, ao norte, com o Planalto do Interflúvio Amazonas-Orenoco; ao oeste com os Planaltos Dissecados Norte da Amazônia; a leste com a Depressão de Boa Vista; e, ao sul, com o Pantanal Setentrional. A porção norte é marcada pela presença de inselbergues, localmente denominadas serras, sendo as mais conhecidas apelidadas Calango, Alemanha, Machado e Trovão. No extremo sudeste, próximo ao rio Alalaú surgem colinas amplas, suaves com morros isolados.

A Depressão de Boa Vista abrange a região nordeste do estado, sendo flanqueada pela Depressão Marginal Norte do Amazonas. Representa $7 \%$ do território estadual com altitudes entre 100 e 130 metros. A paisagem plana, pontilhada de lagoas circulares, pode ser confundida com as superficies deprimidas contiguas, denominadas regionalmente lavrado. Nos depósitos sedimentares fluviais plio-pleistocênicos são comuns os extensos areais, entremeados de superfícies suavemente onduladas, os tesos, modelados em crostas lateríticas. A rede de drenagem compreende um conjunto de lagoas circulares intermitentes, abastecidas pelo lençol freático e os igarapés, que, junto com os buritis às suas margens, constituem as veredas.

O Pantanal Setentrional está localizado na porção sul-sudeste de Roraima, compreendendo $21 \%$ da superficie estadual, e está encaixado na Depressão Marginal Norte do Amazonas. A cobertura é formada por terrenos arenosos inundáveis na estação chuvosa, derivados das rochas proterozóicas do embasamento cristalino. Extensos campos de dunas surgem no norte e nordeste da região pantaneira. Além do rio Branco, os principais cursos d'água são os rios Xeriuini, Jufari, Água Boa do Univini, Itapará, Anauá, Catrimâni e Jauaperi. Nesta região estão situados o Parque 
Nacional do Viruá, o Parque Nacional Serra da Mocidade e a Estação Ecológica Niquiá.

Cavernas, furnas, penhascos e rochedos são testemunhas dos ambientes pretéritos, lugares onde tribos primitivas elaboravam artefatos para caça dos animais pertencentes a espécies extintas havia muito tempo. Registros rupestres deixados por comunidades da idade da pedra adornam uma infinidade de lajedos, grutas e paredões abruptos à beira dos rios. Geossitios são geótopos onde há significativa ocorrência de geomonumentos, representados pelas esculturas do relevo, fósseis de árvores ou animais e artefatos primitivos, como pontas de flechas, lanças e vasos utilitários. A Pedra Pintada, situada na Reserva Indígena São Marcos, no município de Pacaraima, é uma combinação de ambos. 0 monumento lítico, com mais de 35 metros de altura, guarda registros da passagem gravados em hieróglifos pelas tribos primitivas, de grande valor arqueológico e geoturístico. No local, denominado Sítio Arqueológico da Pedra Pintada, há ocorrência de artefatos dos povos ancestrais, como pontas de flechas, cachimbos e vasos de cerâmica. Todavia, o acervo patrimonial geológico do estado de Roraima é escasso, pois são raros os monumentos geológico-geomorfológicos. Exceção é o monte Roraima, onde está localizado o Parque Nacional Monte Roraima, cuja elevação, propriamente dita, está situada $85 \%$ no território da Venezuela, $10 \%$ em terras da República Cooperativa da Guiana, e apenas

\section{$5 \%$ em solo brasileiro.}

No livro "Geodiversidade do Estado de Roraima", publicado pelo CPRM (2014), são apresentados como patrimônio geoturístico lagos, rios, cachoeiras e corredeiras, com também áreas intensamente degradadas, nos municípios de Uiramutã e Mucajaí, onde os destaques são as voçorocas ocasionadas pela intensa atividade garimpeira. Certamente, esses "atrativos turísticos" não se enquadram numa exigência básica do geoturismo, que é a geoconservação, ou seja, a conservação do patrimônio geológico. Outro setor apontado pelo CPRM, como potencialmente geoturístico, é o extenso campo de dunas quaternárias localizado no sul do estado, cuja cobertura vegetal original é removida para retirada dos bancos de areia utilizados na construção civil.Acrescente-se à paisagem geoturística roraimense as geoformas resultantes da construção dos termiteiros em forma de pagodes, encontrados, sobretudo nas colinas com coberturas lateríticas e nas suas encostas e vales (Figuras 5, 6, 7 e 8). Os pagodes são encontrados em grandes concentrações nos municipios de Boa Vista, Bonfim e Pacaraima, principalmente. Todavia, em razão do transporte fluvial alguns exemplares são encontrados nas várzeas do Baixo Rio Branco. Nestes lugares, por uma questão de sobrevivência da espécie, os cupinzeiros são erguidos utilizando como suporte estacas de cercas, árvores e postes. Mantendo, todavia, a arquitetura original em pagode.
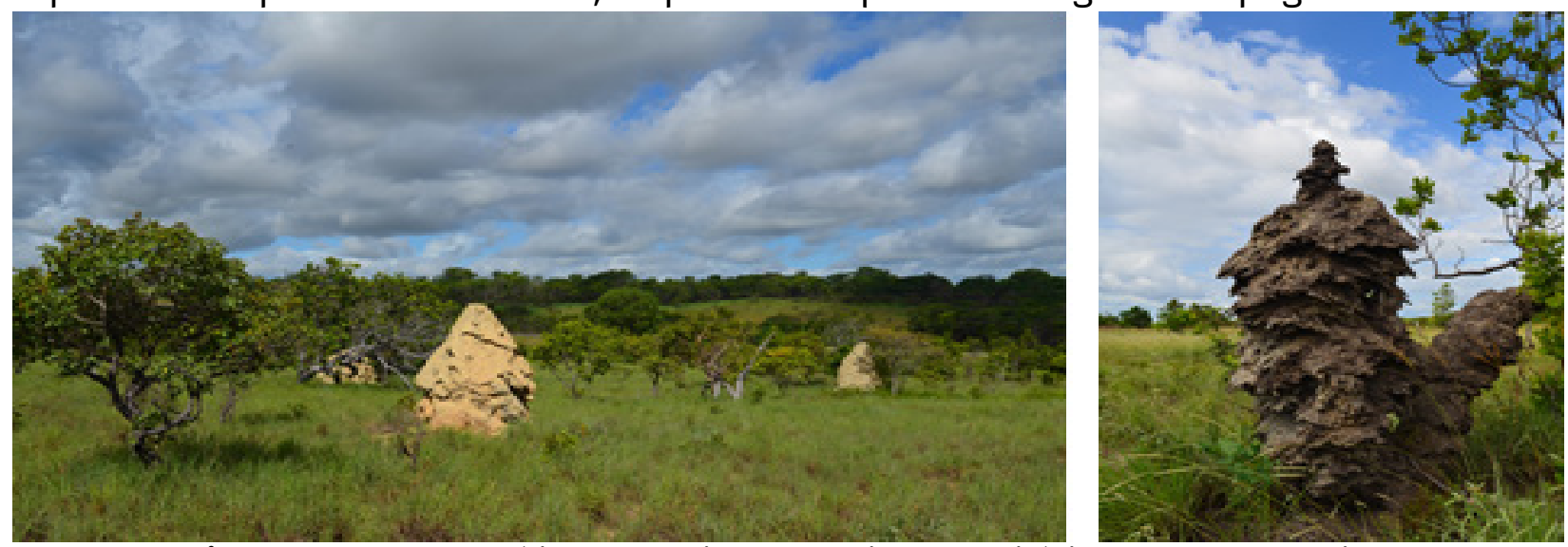

Figuras 05 e 06: Geossitios de "cupins pagodeiros". Município de Bonfim, Roraima Fonte: Giovanni Seabra, 2019. 

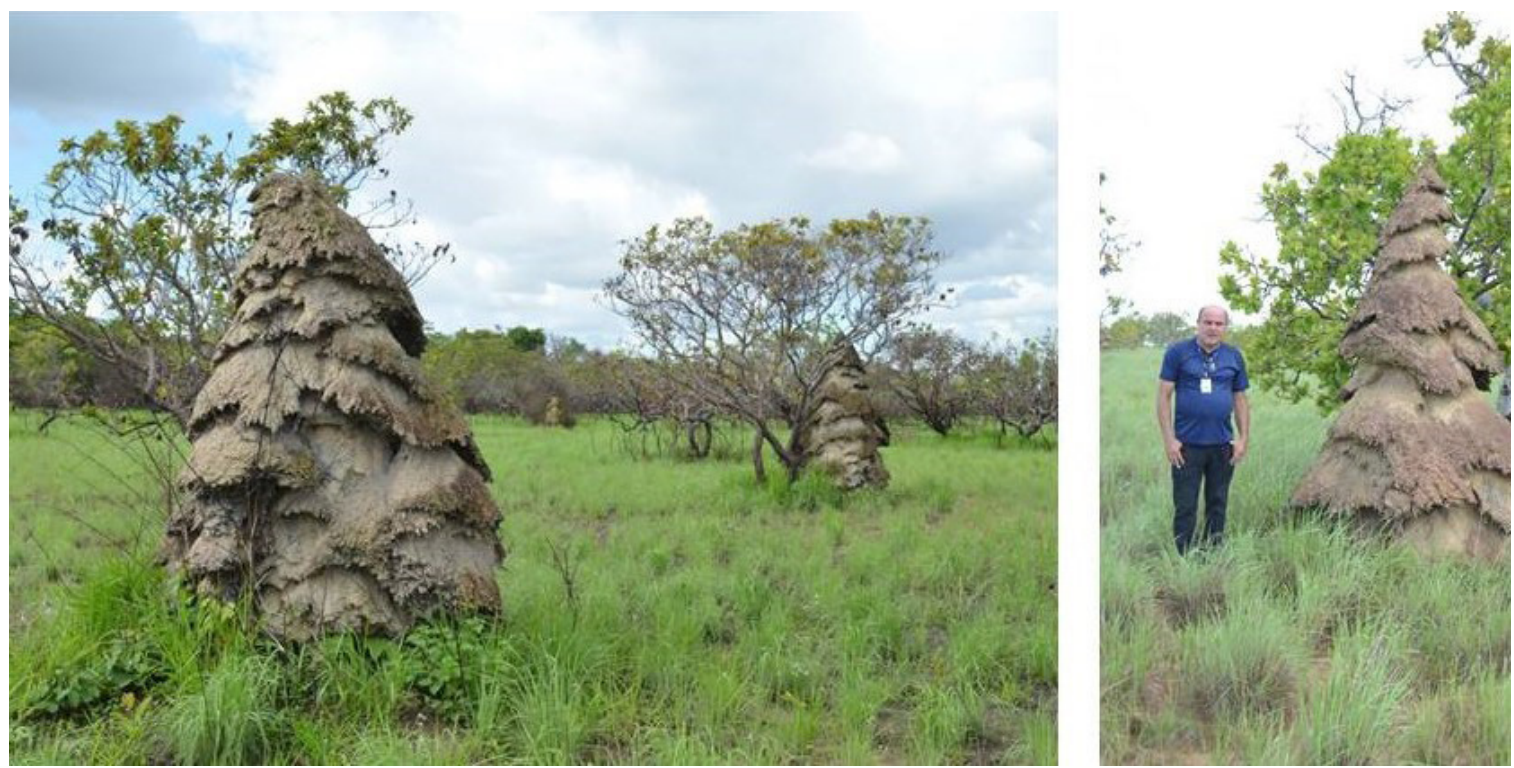

Figuras 7 e 8: Termiteiros no formato "pagode". Municipio de Boa Vista-RR

Fonte: Giovanni Seabra, 2019.

Todavia, urge programas e ações habitat natural, com o uso de máquinas voltados à preservação da geodiversidade em pesadas na limpeza do lavrado e aeração território roraimense, haja vista a velocidade para o cultivo de soja, principalmente, e da degradação dos geomonumentos, devido outros cultivares. Por conseguinte as colônias às intervenções predatórias movidas, dos térmitas "pagodeiros" se retiram do seu sobretudo, pelo modelo de desenvolvimento habitat natural procurando instalar-se em implantado e a ausência do poder público, em locais mais apropriados, como mourões das nível federal, estadual e municipal. Exemplo cercas, postes e buritis nativos dos igarapés das ações ambientalmente devastadoras (Figuras 9 e 10).

é a expulsão das colônias de cupins do seu
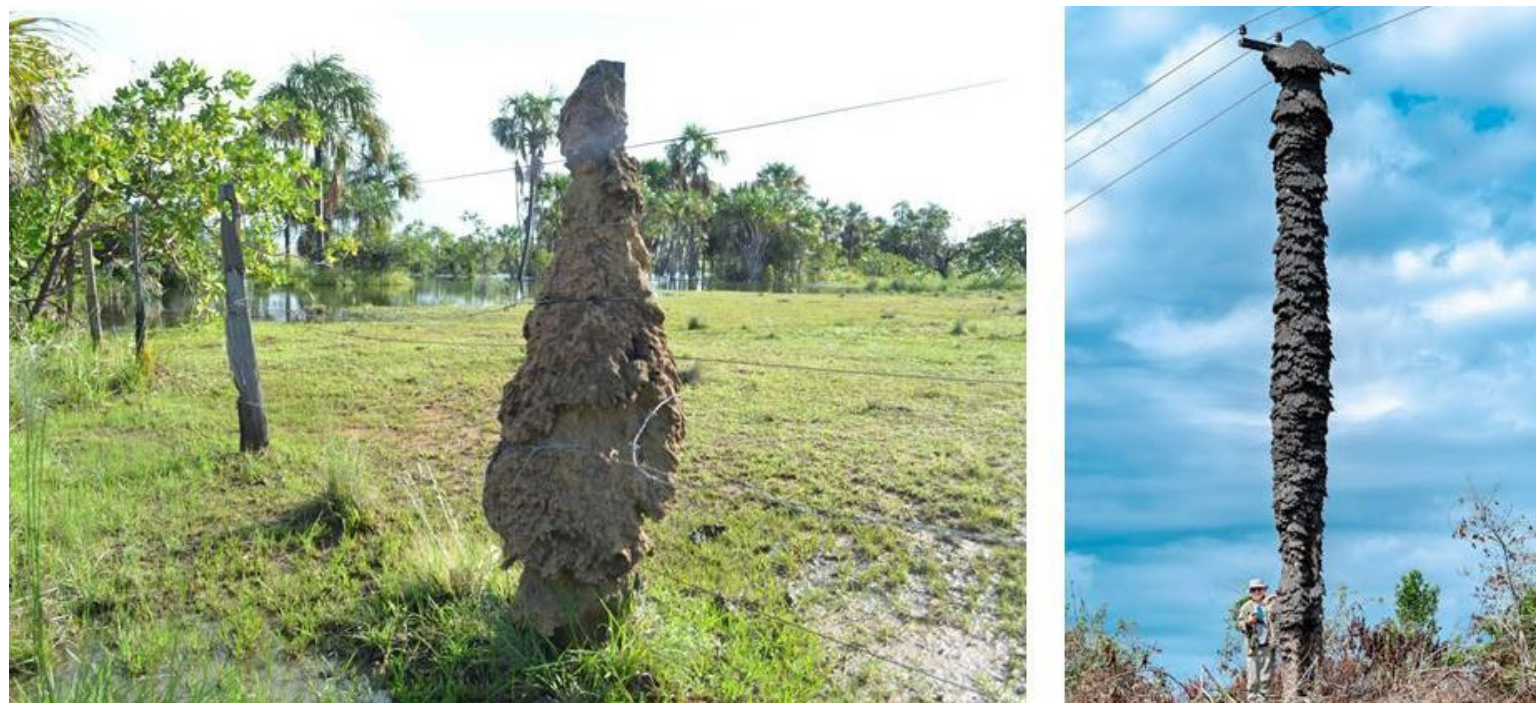

Figuras 09 e 10. Cupins refugiados instalados nas cercas e postes Fonte: Giovanni Seabra e Renato Lima, respectivamente, 2019. 


\section{CONSIDERAÇÕES FINAIS}

Boullón (2002) apresenta a zona turística como uma superfície de extensão variável que corresponde à estruturação de um espaço turístico intermunicipal de um país. Nesse contexto surgem os geoparques representando grandes extensões territoriais regionais que apresentam atrativos geoturísticos, hídricos, biodiversidade e patrimônio cultural. Salientamos no presente trabalho as zonas geoturísticas e locais geoturísticos potenciais no estado de Roraima, os quais exigem uma atenção especial por parte do setor privado e órgãos públicos.

O aproveitamento das capacidades produtivas básicas causa impacto positivo na economia regional, norteando a sustentabilidade local e criando alternativas à implantação de grandes projetos turísticos. Por outro lado, as empresas de turismo que operam nas pequenas localidades monopolizam e capitalizam todos os seus beneficios, restando muito pouco ou quase nada para os moradores. As grandes operadoras e redes hoteleiras são incentivadas através das diretrizes e ações do planejamento oficial. Os planos estratégicos governamentais vinculam-se às regras do modelo econômico concentrador de capital, menosprezando o desenvolvimento regional sustentável.

O turismo devidamente planejado e estruturado mediante os princípios da sustentabilidade ambiental, cultural, econômica esocial favorece o desenvolvimento da economia local e regional, proporcionando rendimentos adicionais à população como um todo. Em geral, locais com planejamento desenvolvido cuidadosamente e com a participação da comunidade local alcançam mais sucesso em termos de satisfação por parte dos visitantes, beneficios econômicos e mínimos impactos negativos sobre o local (Timothy, 1998). Assim, quando os residentes participam de todas as fases de planejamento e implantação do projeto turístico, aumenta as possibilidades de melhoria dos seus padrões econômicos, a qualidade de vida, o nível educacional, sem o comprometimento do patrimônio natural e cultural.

No planejamento participativo, cada comunidade deve identificar seus próprios objetivos, desejos e atividades que refletem a realidade vivida. Sem a inclusão dos residentes nas diversas fases de planejamento e execução do plano turístico, aumentam as chances de prejuízos econômicos potenciais e perda da identidade cultural causados pela imposição dos padrões econômicos globais.

Para o planejamento turístico, a fenomenologia auxilia na compreensão do espaço vivido, este de importância preponderante na busca identidade do lugar e de sua vocação turística. Entre outros fatores, a realidade social contém uma dimensão estética, e a Geografia cumpre o papel de compreender o imaginário contido nessa realidade, através da abordagem humanística (Lencioni, 1999). A preocupação do espaço vivido coloca no centro a análise do lugar, porque nele se distingue o gênero de vida dos povos. Portanto, o treinamento e a capacitação da mão-de-obra devem adequar-se ao contexto social reinante no lugar, priorizando-se os indivíduos que estão fora do mercado de trabalho e gerando oportunidade de renda para as famílias. Para tanto, é oportuno o respeito aos hábitos culturais, adequando-os e inserindo-os como atividades de entretenimento ao turista.

É pertinente estruturar os roteiros geoturísticos com base na geoconservação, de modo a preservar e garantir a perpetuidade dos monumentos naturais, aqui denominados geomonumentos. 0 envolvimento direto das comunidades locais nos projetos turísticos sustentáveis contribui para a criação de rotas de ligação entre os locais que integram as zonas turísticas. O agrupamento dos municípios turísticos e potencialmente turísticos em zonas reduz os custos do investimento em infraestrutura e serviços. 
Os circuitos assim concebidos encurtam as distâncias e possibilitam maior mobilidade e entretenimento ao visitante. Aumentando o número de lugares visitados, o turista tem mais oportunidades para conhecer atrativos diversos e vivenciar os hábitos, mitos, ritos e festejos característicos de diferentes comunidades.

Além dos atrativos turísticos, as zonas geoturísticas deve contar, em seu território, com equipamentos e serviços, infraestrutura de estradas, vias de acesso, transportes, assim como placas de sinalização e educativas autoexplicativas, relacionando entre si os diversos elementos que compõe o espaço turístico. Os arranjos produtivos locais e os principais centros de comercialização dos produtos materiais e imateriais, como as feiras livres, os mercados públicos e os povoados tradicionais constituem importantes locais para visitação turística.

A diversificação dos atrativos turísticos nosroteirosincentivaa circulação dosvisitantes por toda a zona turística, beneficiando um maior número de pessoas. Qualquer projeto turístico tem êxito garantido na medida em que são considerados os fatores endógenos e exógenos do desenvolvimento, de forma a valorizar a dinâmica socioeconômica e cultural do lugar, mediante a mobilização integral da população local.

\section{REFERÊNCIAS}

AB'SABER, A. N. Um Conceito de Geomorfologia a Serviço das Pesquisas sobre o Quaternário. Geomorfologia (18). São Paulo: IGUSP, 1969.

BENI, M. C. Análise estrutural do turismo. São Paulo: Senac, 1998.

BERTRAND, G. Paisagem e Geografia Física Global - esboço metodológico. Cadernos de Ciências da Terra. (13). São Paulo: IGUSP, 1971.

BOUllón, R. C. Planejamento do espaço turístico. Bauru: EDUSC, 2002.

DEAN, Warren. A ferro e fogo: a história e a devastação da Mata Atlântica brasileira. São Paulo: Companhia das Letras, 2013.

EMPRESA DAS ARTES. Tourist Guide Roraima: Ecology, History and Culture. São Paulo, 2009.

IBGE/Instituto Brasileiro de Geografia e Estatística. Dados Censitários. Rio de Janeiro, 2015.

HOLANDA, Lêda R.; MARMOS, José Luiz; MAIA, Maria Adelaide. (Orgs.) Geodiversidade do Estado de Roraima. Manaus: CPRM, 2014.

LADEIRA, L. F.B.;DANTAS,M.E.Compartimentação Geomorfológica. In HOLANDA, Janólfta L. R.; MARMOS, José Luiz; MAIA, Adelaide M.. (Orgs.). Geodiversidade do Estado de Roraima. Manaus: CPRM, 2014. (31-46).

LENCIONI, S. Região e Geografia. São Paulo: EDUSP, 1999.

MARION, N. M. \& FARELL, B. C. A. tale of tourism in two cities. Annals of Tourism Research, 20 (336-353). London, 1998.

RÖLKE, P. Wander \& Naturfüher: Sächsiche Schweis. Band 1. Dresden: Berg- \& Naturverlag Rölke, 2006.

Wander \& Naturfüher: Sächsiche

Schweis. Band 2. Dresden: Berg \& Naturverlag Rölke, 2006.

ROSS, J. L. S. Análise e Síntese na Abordagem Geográfica da Pesquisa para Planejamento Ambiental. Revista do Departamento de Geografia, № 9. FFLCH/USP, São Paulo, 1995.

SEABRA, Giovanni F. Turismo de Base Local no Nordeste Brasileiro. In NASCIMENTO, Ângela; LIMA, Marcos Costa. (orgs). 0 Nordeste Brasileiro em questão: uma agenda para 
reflexão 2. (389-418). Recife: Sudene, 2016.

Paraíba. João Pessoa: Editora

Universitária / UFPB, 2014.

.Turismo Sertanejo. João Pessoa:

Editora Universitária / UFPB, 2007a.

Potencial Geoturístico no Nordeste Brasileiro. Caminho das Pedras: a paisagem sertaneja e o lugar do turismo. In Anais do I Simpósio de Geografia Física do Nordeste. Universidade Regional do Cariri. Crato, 2007b.

Caminho das Pedras. O turismo ecológico de base geológica no Agreste Pernambucano. Relatório de Pós-Doutorado. Recife: Departamento de Geologia / CTG / UFPE, 2004.

Ecos do Turismo: o turismo ecológico em áreas protegidas. Campinas: Papirus, 2001a.

Pesquisa Científica: o método em questão. Brasília:Editora UNB, 2001b.

Do Garimpo aos Ecos do

Turismo: o Parque Nacional da Chapada Diamantina. Tese de Doutorado. São Paulo: FFLCH / USP, 1998.

da Região Cárstica de Andaraí: uma contribuição à conservação de cavernas. Dissertação de Mestrado em Geografia Física. Recife: CFCH / UFPE, 1991.

SEABRA, G. F.; Neu, C. O turismo no espaço rural da Chapada Diamantina. Anais do CITURDES - IV Congresso Internacional sobre Turismo Rural e Desenvolvimento Sustentável, Joinville, 2004.

SCHOBBENHAUS, C.; SILVA, C. R. (Orgs.). Geoparques do Brasil: Propostas. Vol. 1. Rio de Janeiro: CPRM, 2012.

SOTCHAVA, V. B. O Estudo dos Geossistemas. Métodos em Questão. (16). São Paulo: IGUSP, 1972

TIMOTHY, D. J. Cooperative tourism planning in a developing destination. Journal of sustainable tourism. V. 6, n. 1. London, 1998 